\title{
Taking social and environmental factors into account in the investment decision-making process: What can fund managers do to meet clients' needs?
}

Received: 4th September, 2000

\section{Karen Eldridge}

Set up in 1983, EIRIS (the Ethical Investment Research Service) provides research into companies' social, environmental and ethical performance through its software product, Ethical Portfolio Manager. EIRIS also advises clients on the development, monitoring and implementation of ethical investment policies. Karen Eldridge is Head of Client Services at EIRIS, with responsibilities for its marketing strategy and relations with the press. She has worked at EIRIS for ten years.

\begin{abstract}
A recent regulation requires pension fund trustees to disclose how far they take account of ethical, social and environmental issues in their investment policies. This is having an impact on fund managers, as trustees are delegating the implementation of such policies to them. This paper looks at points fund managers need to consider in determining how to take account of their clients' needs in this area and describes different ethical investment strategies. It also gives the business reasons for incorporating social and environmental factors into the investment decision-making process.
\end{abstract}

Keywords: ethical investment; socially responsible investment (SRI); fund manager; trustee; pension fund

Karen Eldridge Ethical Investment Research Service (EIRIS), 80-84 Bondway, London SW8 1SF.

Tel: 0207840 5700; Fax: 02077355323

\section{Introduction}

In July 1998 the Government first announced that it was considering the introduction of a regulation that would require pension fund trustees to disclose their policy on ethical investment. In this time the shift in the pensions world towards social, environmental and other ethical issues has been remarkable. Lawyers and pensions consultants soon began to debate how social and environmental factors could be incorporated into investment policies. Now most pension fund managers are developing ethical policies either for all their clients, or to be available on request for those clients who show particular interest. The most popular method being adopted by fund managers is an 'engagement' strategy, involving dialogue with companies on the ethical issues that the managers believe affect financial performance.

\section{The disclosure regulation}

From 3rd July, 2000 trustees of occupational pension schemes have had to state their policy on ethical investment in their Statement of Investment 
Principles (SIP). To quote the regulation, ${ }^{1}$ matters that trustees need to cover are:

- the extent (if at all) to which social, environmental or ethical considerations are taken into account in the selection, retention and realisation of investments; and

- their policy (if any) directing the exercise of rights (including voting rights) attaching to investments.

This means that while trustees are not obliged to take account of social, environmental or ethical considerations in their investment strategies, they do have to state whether or not they do so.

This disclosure requirement is likely to be extended in the future. The Company Law Review includes a proposal that companies should be required to include details of their performance against corporate governance standards in their annual reports. The Department of Social Security has said that if the proposal is accepted it will probably pass a similar regulation requiring pension scheme trustees to report progress against their socially responsible investment (SRI) policy in their annual reports. ${ }^{2}$

\section{What does the regulation mean for fund managers?}

Already many pension funds are responding positively to the regulation. A survey by Environmental Resource Management ${ }^{3}$ showed that 21 of the 25 largest funds intend to implement an SRI policy. These include the three largest funds, BT, British Coal and the Universities Superannuation Scheme. If annual reports are required to contain trustees' investment approach to environmental and social factors, as outlined above, then details of any ethical policy will be more readily available to scheme members. Given that over three-quarters of pension scheme members think their fund should operate an ethical policy, ${ }^{4}$ this is likely to encourage trustees to establish ethical investment policies, or to develop further existing ones.

Many trustees are turning to their fund managers to determine the approach that they should take and to implement the policy on their behalf. Some trustees have mandated their fund managers to take into account social and environmental factors insofar as they affect companies' financial performance, when selecting the shares in which they invest the scheme's assets. Others have asked fund managers to engage with companies on issues of concern.

Several fund managers have disclosed how they intend to meet clients' needs in this area, or to take social, environmental and other ethical factors into account in their investment strategies generally. Such fund managers include the Prudential, Phillips and Drew, Schroders, Deutsche Asset Management and Scottish Equitable. The Prudential intends explicitly to screen all of its potential UK equity investment on a range of environmental and ethical issues. This move has been prompted by sound business motives, on the basis that a good environmental record may be a sign of long-term financial potential. ${ }^{5}$

Phillips and Drew says that it will be taking a 'focused engagement' approach, concentrating on corporate environmental policy, management and reporting, human rights and employment standards. ${ }^{6}$ Deutsche Asset Management warns there are risks to shareholders from companies which fail to conduct business in a socially responsible manner, and that it will seek to engage companies on the basis of their codes of conduct to assess 
their awareness of and sensitivity to reputational risk. ${ }^{7}$

\section{What are the advantages of embracing the new regulation?}

Apart from meeting clients' needs, there may be other good business reasons for taking social and environmental factors into account in the investment decision-making process:

- Studies suggest that investment performance can be affected by companies' records in areas such as employment, social impact, and pollution control. Fund managers are starting to investigate the nature of these links.

- Paying attention to social and environmental issues can characterise a business that is well-managed generally.

- Fund managers who look for an ethical approach in the companies they select, or who encourage companies to improve their practice, learn more about each company and any potential risks of which they might otherwise have been unaware.

- Increased ongoing understanding of a company, and its direction, aids decisions about whether to add or reduce the size of holding in its stock, as well as how to respond to developments such as takeovers, rights and other share issues.

\section{House approaches}

Approaches that fund managers may want to consider can be divided into 'house' and 'tailor-made' approaches. House approaches are based on issues and a strategy developed by the fund manager, while tailor-made approaches entail implementing the client's own ethical investment policy. Many fund managers may wish to combine both approaches, developing their own house style suitable for most clients, while having the capability to implement bespoke ethical policies for particularly large or important clients.

Two models for developing house approaches are given below.

\section{Share price influence}

Fund managers implementing this approach would apply it across the entire investment portfolio, because they believe that taking into account social and environmental factors in the investment decision-making process will improve shareholder value. In particular, fund managers may look for indicators of reputation risk. They could then use a preference strategy, applying a higher than usual market weighting to those companies assessed to be managing risks well, and investing less in those which do not have a good risk management strategy. Fund managers could also use an engagement approach if they believe this will improve a company's policies or practices and that any such change will increase the value of the company's shares.

\section{Ethical option for clients who want it}

This approach might take into account issues of commonest concern. If implemented through a screening or preference strategy, fund managers might want to back-test the policy to measure the effects on financial performance. The ethical option approach could also be implemented using an engagement strategy, targeting, for example companies operating in a high environmental impact area which do not have good environmental management systems in place. 


\section{What decisions do fund managers need to make?}

There are a number of areas that fund managers may find it helpful to consider when looking at which sort of house approach to develop. This section looks first at factors concerned with the fund manager's organisational structure, and secondly at matters relating to the implementation of the house policy.

\section{Organisational structure}

- How does SRI fit with the fund manager's overall business strategy? Is it an area they wish to take a lead in? Or is it a project for a small team, to deal with the needs of particularly enthusiastic clients?

- What resources are available? Engagement strategies are likely to be quite labour-intensive, as they require fairly extensive communication with companies, good record-keeping, and systems for follow-up, monitoring and reporting. Preference strategies may require analytical software to ascertain the effects on risk and return. Fund managers will also need to look at their compliance systems, to ensure that house SRI approaches and individual client SRI mandates are properly implemented.

- How tailored are the services provided to individual client requirements? And what is the client base? If the fund manager has quite a centralised structure, then it may prefer to develop a house approach. If bespoke services form a major part of the organisation's business, then systems will be in place that allow tailor-made SRI strategies to be implemented. If the fund manager has a number of local authority clients, it will probably be familiar with environmental issues. Similarly, those with a range of charity clients may have an understanding of other ethical concerns, such as Third World issues. They will also have experience of implementing different investment strategies for different clients. As a general rule, fund managers will find it much easier to develop SRI approaches that are compatible with existing systems, than to try to develop new approaches from scratch.

- Does the proposed strategy fit with the fund managers' investment style? Preference strategies may work well with asset allocation-based investment, where fund managers are accustomed to adjusting sector weightings according to different factors. Reputational risk could be another such factor. Engagement strategies may be better suited to stock-picking styles of investment, as engagement requires greater knowledge of individual companies. Those managing mostly passive funds may want to develop ethical indices or focus on engagement strategies.

- How much contact does the fund manager have with companies? If communication levels are quite high, especially on ethically-related issues such as corporate governance, then it may be relatively easy to build on this and incorporate social and environmental issues.

- Does the fund manager operate an ethical policy already for one of its funds, or in a branded in-house fund that the group already markets? If so, it may be possible to use this policy as a blueprint from which to formulate an overall house policy and to begin the process of designing client-driven policies.

- Alternatively, what ethical policies have trustee clients developed already? Checking these offers the opportunity to clarify how the policy may work 
in practice, and how it may develop. This process should also help the fund manager to formulate a house policy to offer other clients who have not yet drafted an ethical policy.

\section{Implementation}

- Who will be in charge of monitoring compliance with clients' ethical investment policies? If the fund manager already manages an ethical fund, or has charity clients with ethical policies, the systems used for monitoring compliance may be adapted for pension fund clients.

- Who will be responsible for coordinating practice for all the fund managers within the group? One approach could be to make one individual, or team, a centre of expertise or point of reference.

- Are there technical or software implications relating to the implementation of the ethical policy? If so, the team is likely to need to include an information technology expert from a very early stage.

- How will the fund manager report to pension fund clients on the investment performance of their funds? Fund managers will need to be able to demonstrate an understanding of the links between the ethical selection process and financial performance. They will also need clear audit trails showing the action they have taken, their reasons for doing so, and the effect on the portfolio or on individual companies.

\section{Three strategies for implementing ethical investment policies}

There are three broad strategies for implementing ethical investment policies:
1 Engagement strategies: The fund manager identifies areas of improvement in the ethical, social and environmental policies of the companies invested in, and encourages them to make those improvements. Methods of effecting this are:

(a) informing companies of the ethical policy and letting them know how it affects investment decisions and responses to takeovers and share issues; (b) trying to persuade companies via regular meetings to improve their practices on particular issues such as employment practices, recycling, and pollution reduction;

(c) offering to help companies formulate their own policy. This can be done through existing corporate governance voting policies by extending them to include ethical issues. The NAPF's Voting Issues Service offers lists by industrial sector of how companies can respond in practice to social and environmental concerns, which may provide a useful starting point.

2 Preference strategies: Fund managers work to a list of guidelines which the trustees prefer companies invested in to meet. They then select investments or stock weightings, taking into account how closely a company meets, or sets about meeting, these parameters. This approach also enables fund managers to integrate ethical and financial decision-making: in cases where companies have a similar rating against traditional financial indicators, these can be compared with the ethical indicators, and companies with the better all-round performance selected.

3 Screening strategies: Trustees ask their fund manager to limit investments to a list of companies selected (screened) for their ethical behaviour. They may be companies involved in 'positive' 
conduct such as good employment practice or actively reducing levels of pollution. Or they may be selected for not indulging in certain 'negative' practices or proscribed industries. This strategy is unlikely to be widely used for segregated pension fund portfolios, due to possible problems of diversification or volatility against a benchmark. However, one version of a screening strategy is to offer a screened fund as an option for Additional Voluntary Contributions (AVCs), or in money-purchase schemes. Fund managers could set up an ethically screened pooled fund for this purpose. Those with an ethical fund already may be able to adapt it for AVC and money-purchase markets.

\section{Questions and answers}

Q I've been asked to develop our corporate governance policy to take account of social and environmental issues. Where do I start?

Companies that are managing their responsibilities in these areas properly are less likely to experience problems relating to risk and reputation. Engaging with companies on such issues, and encouraging them to put appropriate systems in place, may help improve their financial performance.

Some questions that will need to be addressed are:

- Which issues should we engage with companies on?

- Which companies should we engage with?

- What engagement methods should we use?

The extent of the engagement activity will depend in part on the resources available. It may be best to focus on a few companies, on just one issue, to begin with. For example, companies that source goods from the Third World could be encouraged to develop codes of conduct to improve working conditions for their suppliers.

For the engagement strategy to be credible, clear processes and disclosure are essential. The fund manager will need to set out the engagement objectives, both overall and for individual companies, and to keep a careful log of progress. They will also need to provide evidence of the efforts that have been made, and ideally, the results. They will also need to think about what action should be taken if a company refuses to cooperate.

Q How can I set about finding out how social and environmental issues may affect financial performance?

This is often the first step in developing a preference strategy. If the fund manager can identify factors that have resulted in outperformance in the past, these could be analysed to see if they may lead to outperformance in the future.

A step-by-step approach to finding out how social and environmental issues may affect financial performance could be:

- decide the issues to take into account

- choose indicators that measure good or poor performance in relation to these issues

- identify the companies that meet the indicator(s)

- use risk analysis software to backtrack the performance of these companies against a benchmark, such as the FTSE All Share Index, over a suitable time period.

For example, one issue that fund managers may want to consider is the effect of 
environmental policies on financial returns. One indicator to measure performance in this area is the quality of companies' environmental management systems. A clear methodology for measuring the quality of such environmental management systems would be needed to make it possible to differentiate between companies on this basis.

Q We have several clients with ethical policies, especially charities, and some of our local authority clients have asked that issues relating to sustainable development are taken into account in the investment strategy for their funds. How can I keep them all happy?

For charity clients, fund managers might want to create portfolios tailored to the requirements of each. Alternatively, if there is quite a lot of overlap between the ethical policies, a model portfolio could be set up which takes into account most issues of concern, tweaking it for individual clients with particular needs.

For example, if the charity client base comprises mostly religious organisations, then the main concerns to address would include tobacco, alcohol, gambling and weapons production. A model portfolio could be established that excludes companies involved in these activities. However, fund managers may have charity clients with other concerns. To address their needs, the portfolio could be tweaked by excluding companies whose activities might conflict with their objects. Animal welfare charities might wish to exclude investments in companies that carry out animal testing or which run factory farms, for example.

For local authority clients, a model portfolio could be set up that addresses issues relating, for example, to sustainable development, to complement their Local Agenda 21 responsibilities. This could be established on a preference basis, as described above. One possible strategy might be to aim to invest in 'best in class' stocks.

\section{What will investment consultants be looking for in fund managers?}

Investment consultants have their own criteria for assessing suitable fund managers for a particular scheme on behalf of their trustee clients. However, some additional areas they may wish to explore with a potential fund managers for an ethical mandate are as follows:

- Do they understand how companies are involved in environmental and social issues? Do they have the systems in place to incorporate such factors into the investment decisionmaking process?

- Do they have experience of managing ethically screened portfolios, and over what timescale? How large a part of their business or their future plans is devoted to this and how committed are they to it?

- Do they understand the fund's own ethical concerns, and are they willing to act upon them?

- Will they tailor the fund's investments to suit the concerns of the ethical investment policy, if required? Or are they likely to urge trustees to put the fund into the same approach they have developed for others?

- Can they explain any financial implications of the approach agreed by trustees?

- What internal resources do they have for researching social and environmental issues? What external resources are used?

- How will they report to trustees on how the SRI policy has been implemented, what action has been taken, and what effect this has had? What is their voting record and 
stance on corporate governance issues? Do they exercise proxy votes on behalf of the pension funds they manage, and if so how do they decide which way to vote?

- Do they have policies and public statements on social and environmental issues eg, in-house environmental programmes?

- Are they involved in external initiatives and policy developments? Are they, for example, members of the UK Social Investment Forum?

\section{Conclusion}

Developing policies to take account of environmental, social and ethical considerations in investment strategies is likely to be an iterative process. Trustees will probably want to take some fairly small steps to begin with, and then develop their policies further when they and the pensions industry have a better understanding of the issues involved, the different strategies for developing and implementing SRI policies, and the systems needed to monitor and report on the effectiveness of those policies.

July 3rd 2000 was only the start of a process of integrating these wider social and environmental considerations into pension provision. With increased understanding of links between investment and issues of global concern, more people will expect financial institutions they do business with to heed their concerns about ethical matters. In the future, many more people will be considering how they want to see social, environmental and other ethical concerns affect their investment decisions, and that (partly as a consequence) these issues seem likely to form a larger part of the agendas of both business and the investment community. Fund managers who do not offer any ethical investment selection and monitoring services risk losing competitive edge, both in winning and in retaining investment business in the future.

\section{References}

1 The Occupational Pension Schemes (Investment, and Assignment, Forfeiture, Bankruptcy etc.) Amendment Regulations 1999, SI 1999 No. 1849.

2 Speech given by Adrian Mallen of the DSS at the Northern Pensions Conference, July 2000.

3 Borremans, E. (2000) 'New policies, new demands', Pensions Management, August.

4 EIRIS/NOP Solutions 'Pensions and ethical policies' survey, June 2000. The survey found that 77 per cent of pension scheme members think their fund should operate an ethical policy whenever it can do so without reducing financial return.

5 The Ethical Investor, EIRIS, November/December 1999.

6 Ethical Pensions Learning Network Briefing No. 5, UK Social Investment Forum, June 2000.

7 'Socially Responsible Investment — DAM's perspective and framework for engagement', Deutsche Asset Management Morgan Grenfell, 2000. 